\title{
The Influence Factor of Lean Behaviour Toward Job Performance in Fujitsu Component (Malaysia)
}

\author{
Yunos Ngadiman, Abdul Talib Bon, David Martin, Subatra A/P Krishnan
}

\begin{abstract}
In the past decades, existing researchers have widely ventured the context of lean. Lean behaviour includes one of the practices. Lean behaviour an important practice for developing behaviours that can eliminate the quantity of waste associated with big production line. In Malaysia, while in many businesses the notion of lean can be seen implemented, lean behavior methods appear to be vague. This study is therefore aimed at identifying the connection between lean behaviour factor and job performance in Fujistu Component (Malaysia). The information gathered was evaluated using version 22.0 of the Social Science Statistical Package (SPSS). The results from this study showed a positive connection between Respect for People and Job Performance (coefficient of correlation $=0.393$ ), $a$ positive relationship between Continuous Learning and Improvement and Job Performance (coefficient of correlation $=0.667$ ), and finally a positive connection between Process and Result Driven and Job Performance (correlation coefficient value $=0.840$ ). This means that these factors influence job performance in a positive way.
\end{abstract}

Index Terms: Lean behaviour, job performance, lean manufacturing concept.

\section{INTRODUCTION}

This research is proposed to explore the factors of lean behaviour influencing job performance in Fujitsu Component (Malaysia) Pte. Ltd. Although the notion of lean manufacturing scheme can now be discovered to be quite common, it can be hard to accomplish implementation in real-life situations. In particular in the scope of the Malaysian manufacturing system, relevant case studies concerning lean behaviour were restricted. However, Ramune, 2012, states that the implementation of lean manufacturing philosophy are the reason for business to gain competitive advantage in the current advance growing market. Therefore, this research would like to emphasize on the main contributor to the whole organization which is the man or the workers that involved in the lean process.

Revised Manuscript Received on June 22, 2019.

Yunos Ngadiman, Faculty of Technology Management and Business, Universiti Tun Hussein Onn Malaysia,86400 Parit Raja, Batu Pahat, Johor, Malaysia

Abdul Talib Bon, Faculty of Technology Management and Business, Universiti Tun Hussein Onn Malaysia,86400 Parit Raja, Batu Pahat, Johor, Malaysia

David Martin, Faculty of Technology Management and Business, Universiti Tun Hussein Onn Malaysia,86400 Parit Raja, Batu Pahat, Johor, Malaysia

Subatra A/P Krishnan, Faculty of Technology Management and Business, Universiti Tun Hussein Onn Malaysia,86400 Parit Raja, Batu Pahat, Johor, Malaysia

\section{RESEARCH BACKGROUND}

The lean idea came from a Japanese automobile company earlier known as the Toyota Production System (TPS). The fundamental objective was to eliminate waste and decrease activities that bring the organisation zero value (Norani et al., 2010).

The waste that Rasli, Sha'ri, and Ana Sakura discussed and recognized in TPS in the World Engineering Congress (2011) proceeding lists seven kinds of waste. The waste is: waste of overproduction, waiting inventory, unnecessary inventory, unnecessary shipping, waiting time, unnecessary processing, unnecessary movement and waste of defective products. Three of the seven waste kinds listed engaged employee contact. Workers in the shop floor handle and inspect waste from overproduction, waste from unnecessary processing, and waste from defected products. The issue is that job methods cause modifications to happen as time goes by. This results in fat employee behaviour. Fat behaviour is described as behaviours which do not contribute value and which can be removed (Hamouda et al., 2014). Some fat behaviour characteristics include inaction, random ideas, irrelevant observations, unnecessary comments, interpretations, and so on (Emiliani, 1998). Such behaviour is known to be a type of waste as these aspects do not contribute to the manufacturing as a whole. It is therefore necessary to implement lean behaviour methods.

\section{Problem Statements}

Having interviewed senior managers from Fujitsu Component (Malaysia), a manufacturing firm that creates relays and keyboards, there were few issues linked to the employees' behaviour. Mr. Jeyaseelan, who is a senior manager in the planning department, has 30 years of work experience in the business since 1996, said:

On the Material Requirement Planning (MRP) system, the business tends to have backlog documents.

Inability to execute the task provided at a given time has created a huge manufacturing issue leading to incorrect assessment of the purchase of materials, over manufacturing and excessive inventory.

Massive product defect owing to the mistake of blending the relay component material.

Workers that are in charge of the blending method mixed distinct percentages of material that differed from the original production plan.

\section{Published By:}




\section{Research Objectives}

The goal is to define the important connection that affects job performance between lean behaviour factors.

\section{LITERATURE REVIEW}

In recent years, the context of lean behaviour has been the subject of research by a few researchers. The results of the study are based on factors regarded in lean behaviour. Below is a literature review of the study was carried out in Malaysia and foreign countries. Hamouda et.al (2014)'s study discusses lean behaviour practices in the office department and how lean behavior practices among staff can be applied to create a good job environment. The research also mentioned the weakness and strength of lean behavior and evaluated the connection between lean principles and suggested lean improvement technique. The researcher pointed out nine lean behaviours that should have a good leader at the end of the research. As a consequence of this research, respect for people and ongoing learning and improvement are the primary critical factor that contributes to lean behavioral practices.

Puvanasvaran's (2009) research discusses lean behavior in an aerospace environment that is being examined to determine a year's successful lean implementation. After a year of implementation, the research discussed the distinctions in the outcome of lean behavior practices and identified issue solving capacities to improve the kitting department's lean behavior. The results show that there was a 10 percent improvement in the department after a year of lean implementation. The research also found that the factor Respect for People, Continuous Learning and Improvement, and Process and Result Driven have a connection.

Benjamin's study (2013) explores fat behaviors that prohibit the smooth implementation of lean operations in Trinidad and Tobago. It involves staff from 19 distinct organisations. The researcher mentioned as the primary cause of the issue factors such as ego-driven, low confidence, ignorance, fear and confusion. The researcher concluded that to develop a more productive organization, corrective action should be taken to change the internal culture of organizations.

Beale's research (2007) explores the impact on staff willingness to accept lean behavior practices of multiple individual level factors. The study was performed on a holding company with subsidiaries involved in the growth, manufacture and marketing of pharmaceutical branded and brand equivalent products. The anticipated result of adapting lean behaviors involves making the business more competitive, helping them work smarter, enhancing the company's effectiveness, helping to decrease the company's costs, and more.

Emiliani's (2014) further analysis focuses on leadership behaviors that can cultivate lean within an organisation. The author says that the behavior of people is not always ideal when interacting with employees. There is therefore a tendency for leaders to sometimes behave and misbehave. In reference to Emiliani's award-winning article (1998), Bob Emiliani emphasized that particular lean behaviors such as confidence, patience, consistency, humility, and balance promote data flow within an organisation while fat

behaviors such as elevated ego, manipulative, misleading, and disrespectful do not.

\section{METHODOLOGY}

\section{Introduction}

This section will discuss the techniques to be used to acquire essential information required for this research. This is a quantitative study and the collection of data is done using questionnaire survey that is suitable for this research.

\section{Research Flow}

The research process;



Fig. 3.1 Research Process

\begin{tabular}{|l|l|l|l|}
\hline $\begin{array}{l}\text { Reliability } \\
\text { Analysis }\end{array}$ & $(\boldsymbol{\alpha})$ & $\begin{array}{l}\text { No. of } \\
\text { Questions }\end{array}$ & $\begin{array}{l}\text { No. of } \\
\text { Respondents }\end{array}$ \\
\hline Pilot Test & 0.942 & 23 & 30 \\
\hline Actual & 0.926 & 230 & 246 \\
\hline
\end{tabular}


Conceptual Framework

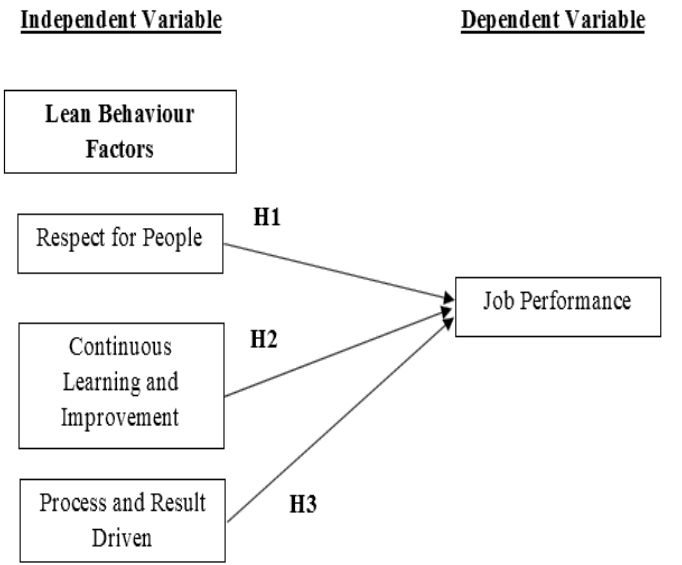

H1: There is a positive relationship between respect for people and job performance.

H2: There is a positive relationship between continuous learning and improvement and job performance.

H3: There is a positive relationship between process and result driven and job performance.

\section{ANALYSIS AND RESULT}

The result of the quantitative data analysis will be presented. For this research, SPSS software was used to analyze the quantitative data.

\section{Response Rate}

Four hundred and seventeen (417) questionnaire forms were initially sent to the company by directly approaching the supervisor of the relay production line and handing it by hand. The questionnaires were then collected back one month later. However, the total forms that was fully answered was only 246 respondents. This means that the response rate is $58.9 \%$ (Table 4.1 ).

Table. 4.1 Percentage for Response Rate

\begin{tabular}{|l|l|}
\hline Items & Total \\
\hline Distributed Questionnaire & 417 \\
\hline Returned Questionnaire & 246 \\
\hline $\begin{array}{l}\text { Total Percentage of Returned } \\
\text { Survey }\end{array}$ & $(246 / 417)=58.9 \%$ \\
\hline
\end{tabular}

The response rate of this research is around $59 \%$ which means that the response rate is considered as a good survey response rate (Biersdorff, 2009). Therefore, this research has achieved the target of response rate.

\section{Reliability Analysis}

\section{Table. 4.2 Cronbach Alpha for Pilot and Actual Test}

The overall reliability test for the pilot test shows more than 0.9 value which indicates a high reliability, excellent and efficient. Overall reliability analysis conducted on 246 respondents shows a Cronbach's alpha coefficient value of 0.926 which is considered excellent and the data is considered reliable and suitable for this research.

\section{Normality Testing}

Table. 4.3 Test of Normality between Lean Behaviour Factors and Job Performance

\begin{tabular}{|l|l|l|l|}
\hline \multirow{2}{*}{} & \multicolumn{3}{|l|}{ Kolmogorov-Smirnov ${ }^{\mathrm{a}}$} \\
\cline { 2 - 4 } & Statistic & df & Sig. \\
\hline comp_A & 128 & 246 & .000 \\
comp_B & .189 & 246 & .000 \\
comp_C & .161 & 246 & .000 \\
comp_Section3 & .105 & 246 & .000 \\
\hline
\end{tabular}

From Table 4.12, Kolmogorov-Smirnov is used to test the normality. The significance value for all the variables are less than 0.05. Hence, the test is significant and the distribution is non-normal.

\section{Inferential Analysis}

i. Correlation between Respect for People and Job Performance

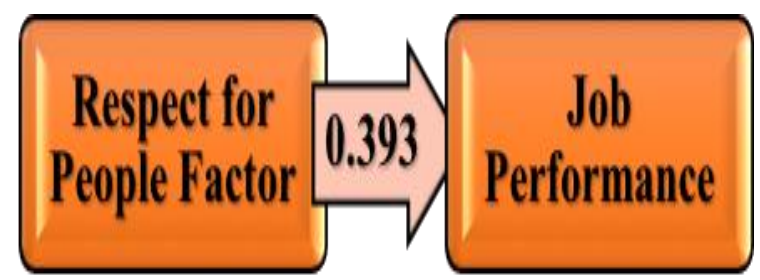

Fig. 4.4 Correlation Coefficient for Respect for People Factor with Job Performance

Based on Table 4.19, the factor respect for people have a weak positive relationship with job performance. The correlation coefficient value is 0.393 . The significant value is less than 0.05 . Hence, the data is significant. Thus, the hypothesis is accepted.

ii. Correlation between Continuous Learning and Improvement and Job Performance

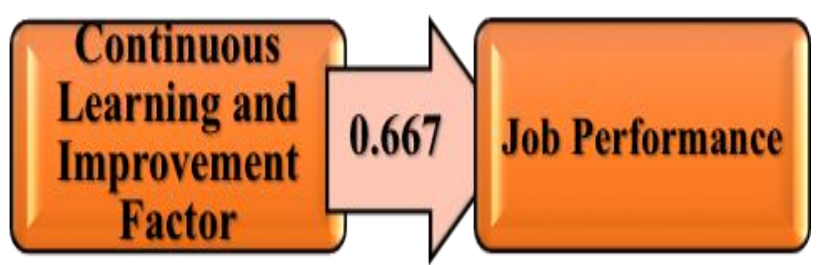

Fig. 4.5 Correlation Coefficient for Continuous

Learning and Improvement with Job Performance

The factor continuous learning and improvement has a moderate positive correlation with job performance. The correlation coefficient value is 0.667 . The significant value is less than 0.05 . Hence, the data is significant. Thus, the hypothesis is accepted.

iii. Correlation between Process and Result Driven and Job Performance 


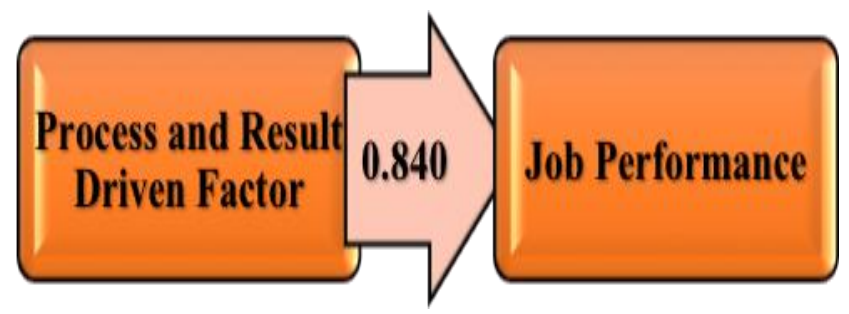

Fig. 4.6 Correlation Coefficient for Process and Result Driven with Job Performance

The factor process and result driven has a high positive correlation with job performance. The correlation coefficient value is 0.840 . The significant value is less than 0.05 . Hence, the data is significant. Thus, the hypothesis is accepted.

\section{DISCUSSION AND CONCLUSION}

\section{Introduction}

This final chapter will discuss, explain and provide brief overview of the research based on the findings that has been analysed in the previous chapter.

\section{Discussion of Findings}

The discussion of this research will be divided according to the objective and hypothesis of the research. The goal of this research is to identify the important relationship between factors of lean behavior and job performance. Before identifying the relationship between the two variables, lean behaviour factors was identified first through past journal reviews. The factors were recognized as human regard, ongoing learning and improvement, as well as process and outcome driven. With the factors identified, hypothesis was created in order to identify its relationship with job performance. The hypotheses are:

Hypothesis 1: There is a positive relationship between respect for people and job performance.

The lean behaviour factor, respect for people had a low positive correlation with job performance. The correlation coefficient value is only 0.393 . The significance value is less than 0.05. Despite the low value, the data is still considered significant. Hence, the hypothesis is accepted. Although the factor respect for people with job performance has the lowest correlation coefficient compared to others, it cannot be denied that respect is connecting factor within a company environment to work as teams to enhance job performance. This is proven through the work of Rego, et al., 2007 whereby employees that exhibit respectful behaviour tends to express their ideas more outspokenly and this increases their intrinsic motivation which enables them to search for new and more effective ways of working. Another past research conducted by Jacobsen in 2013 has also shown that respect is one of the core value in organizations as it plays an important role in organizational engagement to get a job done.

Jacobsen went on to say that if a worker feels like being respected, they are more likely to have an efficient connection with a team, a manager, or the organisation as a whole. Developing an atmosphere with plenty of regard is essential to a smooth manufacturing process. A survey

conducted in Harvard, showed in exact opposite results contrary to this research survey whereby when employee are not treated with respect, $66 \%$ said that their performance declined, $38 \%$ decreased the quality of their work, $47 \%$ decreased the time spend at work, $48 \%$ decreased their work effort and etc. (Porath and Pearson, 2013).

Hypothesis 2: There is a positive relationship between continuous learning and improvement and job performance.

This hypothesis demonstrated a moderate beneficial connection between ongoing learning and improvement and job performance. The correlation coefficient value is 0.667 . The significant value is less than 0.05 . Hence, the data is significant. Thus, the hypothesis is accepted. Despite showing moderate correlation between continuous learning and improvement with job performance, it can be seen that from the results obtained that there is a high importance for employees to always share information and ideas for the company. It is also the responsibility of the company to provide opportunities for employees to improve and enhance themselves. The result obtained is similar to case study from previous researcher whereby the researcher agrees that continuous learning facilitates behavioural change among employees that can lead to improved performance in a business study conducted in Colorado, United States. He went by adding that all businesses competing in an aggressive and unstable environments must pursue the process of learning so that performance can be improved (Slater. F and Narver.C, 2016). In a conference proceedings by J. Pettersen (2008), also emphasized the need for learning and continuous learning. The findings has shown that there is a clear need and focus for employees that implement lean practices to have continuous improvement and implies that some form of learning is required to elevate performances (Pettersen, 2008).

Hypothesis 3: There is positive relationship between process and result driven and job performance.

The hypothesis revealed a highly beneficial connection between process-driven consequence and job performance. The correlation coefficient value is 0.840 . The significant value is less than 0.05 . Hence, the data is significant. Thus, the hypothesis is accepted. The strong positive connection between process and outcome driven and work efficiency demonstrates us that having a clear description of the work they do has an impact on the performance of the job. Employees need to have a sense of responsibility in the process that they are doing in order to achieve a target goal. This can be done by following orders correctly that is given to them to perform a task. A study conducted by Rizwan (2014), proved in that when an employee is unsure of his/her job description, then he/she will not be able to perform the job well. He added that this situation could also lead to job stress.

The findings by Schaffer and Thomson (2000) has also supported the findings of this research by saying that when the nature of the job is result driven, it helps the organization to skip long preparation and procedure and accomplishes the targeted work performance that is needed (Schaffer \& Thomson, 2000).

Published By: 


\section{RECOMMENDATION FOR FUTURE RESEARCHER}

For future researcher, the researcher would strongly suggest different methods of collecting data such as conducting interviews so that respondents can provide their own perspective or opinion instead of the basic theory. This way future researcher will be able pick up minor details or opinions that could not have been included in this research. Next, the future researcher can focus on any other departments of any other company. This is because the issues or problem discussed in this research is seen to be evident even in an office environment based on past literature reviews. The effect of lean behaviour on job performance can even influence other manufacturing industry in Malaysia (Ngadiman et al., 2012).

\section{ACKNOWLEDGMENT}

The researchers sincerely have been appreciating and gratitude an invaluable pronounced to the Registrar Office of Universiti Tun Hussein Onn Malaysia under their guaranteed fund for a sufficient time to enable the researchers were successfully attending to present this paper.

\section{REFERENCES}

1. Beale, J. (2007). Employee Motivation to Adopt Lean Behaviours: Individual-level Antecedents. Annual Conference Dallas, Texas, U.S.A May 4 to May 7, 2007. Pp. 53.

2. Emiliani, B. (2014). Leadership behaviour: The path to lean culture. Retrieved on May 9, 2016 from http://www.bobemiliani.com /leadership-behaviors-the-path-tolean-culture/

3. Emiliani, M.L. (1998). Lean behaviours. Management Decision, Vol. 36, Iss 9, pp. 615-631.

4. Benjamin, C. T. (2013). A Study of Behaviours that Retard the Implementation of Lean Operations. The Journal of the Association of Professiona Engineers of Trinidad and Tobago, Vol.41, No.1, pp. 43-48.

5. Biersdorff, K. (2009). How many is enough? Bright Ideas, Supporting Organizational Excellence \& Innovation. Vol. 1 No.3, pp.1-2

6. Hamouda, A.M.S, Puvanasvaran, A.P., Norazlin, N., C. S. F. (2014). Lean Behavior Impact Towards Lean Management: A Case Study. Journal Of Advanced Manufacturing Technology, Vol.8 No.1, pp.17-32.

7. Jacobsen, Darcy. (2013).The Secret to Respect in the Workplace | Globoforce Blog. Employee Engagement Recognition and Reward Commentary Globoforce Blog RSS. Globoforce Limited, 23 July 2013. Web. 07 Oct. 2014.

8. Ngadiman, Y., Dr Burairah, H., \& Dr Izaidin, A. M. (2012). A study of total productive maintenance implementation in manufacturing industry for generating greater profits. In Proceedings International Conference of Technology Management, Business and Entrepreneurship, Melaka, Malaysia, pp. 157-173.

9. Norani Nordin, Baba Md Deros and Dzuraidah Abd Wahab, (2010). A Survey on Lean Manufacturing Implementation in Malaysian Automotive Industry. International Journal of Innovation, Management and Technology. Vol. 1, No. 4, pp. 374-380.

10. Pettersen, J. (2008). Defining Lean Production: Some conceptual and practical issues. In 11th QMOD Conference: Quality Management and Organizational Development
Attaining Sustainability From Organizational Excellence to Sustainable Excellence, 2008, Helsinborg, Sweden, 20-22 August, 2008. pp. 285-300.

11. Porath, C.and Pearson, C. (2013). The Price of Incivility. Harvard Business Review. January- February Issue.

12. Puvanasvaran, A. P. (2006). Enhancing Productivity Through Lean Behavior. Journal of Applied Sciences Research Vol.3, No.6, pp 298-317.

13. Puvanasvaran, A.P., Megat, M.H.H., Tang, S.H., Muhamad, M.R, A. M. H. (2009). Lean Behavior in Implementing Lean Process Management. Journal of Applied Sciences Research, Vol.5 No.8, pp. 930-943.

14. Ramune Cianiene, Milita Vienazindiene, (2012). Lean manufacturing: theory and practice. Journal of Economic and Management.Vol.17, No.2, pp. 726-732.

15. Rego, A., Sousa, F., Pina, M., Correia, A., \& Saur-amaral, I. (2007). Leader Self-Reported Emotional Intelligence and Perceived Employee Creativity: An Exploratory Study, Vol. 16, No.3, pg.250-264.

16. Rizwan, M. (2014). Antecedents of Job Stress and its impact on Job Performance and Job Satisfaction. International Journal of Learning and Development, Vol.4, No.2, pp.187-203.

17. Schaffer, R. H., \& Thomson, H. A. (2000). Successful Change Programs Begin with Results. Harvard Business Review.

18. Slater, F. and Narver, C. J. (2016). Market Orientation and Learning Organization. Journal of Marketing, Vol.59, pp. 6374.W.-K. Chen, Linear Networks and Systems (Book style). Belmont, CA: Wadsworth, 1993, pp. 123-135.

19. H. Poor, An Introduction to Signal Detection and Estimation. New York: Springer-Verlag, 1985, ch. 4.

20. B. Smith, "An approach to graphs of linear forms (Unpublished work style)," unpublished.

21. E. H. Miller, "A note on reflector arrays (Periodical styleAccepted for publication)," IEEE Trans. Antennas Propagat., to be published.

22. J. Wang, "Fundamentals of erbium-doped fiber amplifiers arrays (Periodical style-Submitted for publication)," IEEE J. Quantum Electron., submitted for publication.

23. C. J. Kaufman, Rocky Mountain Research Lab., Boulder, CO, private communication, May 1995.

24. Y. Yorozu, M. Hirano, K. Oka, and Y. Tagawa, "Electron spectroscopy studies on magneto-optical media and plastic substrate interfaces (Translation Journals style)," IEEE Transl. J. Magn.Jpn., vol. 2, Aug. 1987, pp. 740-741 [Dig. $9^{\text {th }}$ Annu. Conf. Magnetics Japan, 1982, p. 301].

25. M. Young, The Techincal Writers Handbook. Mill Valley, CA: University Science, 1989.

26. J. U. Duncombe, "Infrared navigation-Part I: An assessment of feasibility (Periodical style)," IEEE Trans. Electron Devices, vol. ED-11, pp. 34-39, Jan. 1959.

27. S. Chen, B. Mulgrew, and P. M. Grant, "A clustering technique for digital communications channel equalization using radial basis function networks," IEEE Trans. Neural Networks, vol. 4, pp. 570-578, Jul. 1993.

28. R. W. Lucky, "Automatic equalization for digital communication," Bell Syst. Tech. J., vol. 44, no. 4, pp. 547588, Apr. 1965.

29. S. P. Bingulac, "On the compatibility of adaptive controllers (Published Conference Proceedings style)," in Proc. 4th Annu. Allerton Conf. Circuits and Systems Theory, New York, 1994, pp. 8-16.

30. G. R. Faulhaber, "Design of service systems with priority reservation," in Conf. Rec. 1995 IEEE Int. Conf. Communications, pp. 3-8.

\section{Published By:}


31. W. D. Doyle, "Magnetization reversal in films with biaxial anisotropy," in 1987 Proc. INTERMAG Conf., pp. 2.2-1-2.2-6.

32. G. W. Juette and L. E. Zeffanella, "Radio noise currents $n$ short sections on bundle conductors (Presented Conference Paper style)," presented at the IEEE Summer power Meeting, Dallas, TX, Jun. 22-27, 1990, Paper 90 SM 690-0 PWRS.

33. J. G. Kreifeldt, "An analysis of surface-detected EMG as an amplitude-modulated noise," presented at the 1989 Int. Conf. Medicine and Biological Engineering, Chicago, IL.

34. J. Williams, "Narrow-band analyzer (Thesis or Dissertation style)," Ph.D. dissertation, Dept. Elect. Eng., Harvard Univ., Cambridge, MA, 1993.

35. N. Kawasaki, "Parametric study of thermal and chemical nonequilibrium nozzle flow," M.S. thesis, Dept. Electron. Eng., Osaka Univ., Osaka, Japan, 1993.

36. J. P. Wilkinson, "Nonlinear resonant circuit devices (Patent style)," U.S. Patent 3624 12, July 16, 1990.

37. IEEE Criteria for Class IE Electric Systems (Standards style), IEEE Standard 308, 1969.

38. Letter Symbols for Quantities, ANSI Standard Y10.pp. 5-1968. 